\section{Embolisation of a large carotid body tumour: Anaesthetic implications}

\section{Alka Goyal, Sachidanand Jee Bharti, Girija Prasad Rath}

Sir, Carotid body tumours are extremely rare tumours arising from chromaffin tissue of carotid sinus. Unlike small tumours, surgical excision of large carotid body tumours poses anaesthetic challenges in the form of difficult intubation, massive blood loss and haemodynamic instability owing to catecholamine release. Neuroradiological intervention remains the treatment of choice in such cases. We present the anaesthetic management a case of large carotid body tumour, which protruded into the oropharynx.

An 18-year-old male was admitted to our hospital with complaints of gradual enlargement of neck swelling, hoarseness of voice, difficulty in breathing and dysphagia to solid foods. On examination, a mobile painless mass was found in the left-side of neck near the angle of jaw [Figure 1a]. Intra-oral examination revealed a large pharyngeal mass displacing the uvula to right side [Figure 1b]. All the routine investigations were within normal limit. Urinary vanillyl mandelic acid level was within normal range. The vital parameters were also normal. A diagnosis of large carotid body tumour was made after a plethora of investigations involving computed tomographic scan and magnetic resonance imaging and intra-arterial digital subtraction angiography of head and neck region [Figure 2]. The patient was planned for embolisation of the carotid body tumour, under general anaesthesia, to reduce vascularity and tumour-size. He was pre-medicated with intramuscular glycopyrrolate $0.2 \mathrm{mg}, 30 \mathrm{~min}$ before induction of anaesthesia. In view of anticipated difficult intubation, a 'difficult intubation cart' was kept ready. In the neuroradiology suite, anaesthesia was induced with intravenous propofol $100 \mathrm{mg}$ and fentanyl $100 \mu \mathrm{g}$. Rocuronium $60 \mathrm{mg}$ was given to facilitate endotracheal intubation without any difficulty. The monitoring modalities included electrocardiography, $\mathrm{SPO}_{2}$, end-tidal carbon dioxide $\left(\mathrm{EtCO}_{2}\right)$ and arterial $\mathrm{BP}$.

Department of Neuroanaesthesiology, All India Institute of Medical Sciences, New Delhi, India

Address for correspondence:

Dr. Girija Prasad Rath, Department of Neuroanaesthesiology, Neurosciences Center, $6^{\text {th }}$ Floor/Room No. 9, All India Institute of Medical Sciences, New Delhi - 110 029, India. E-mail: girijarath@yahoo.co.in 


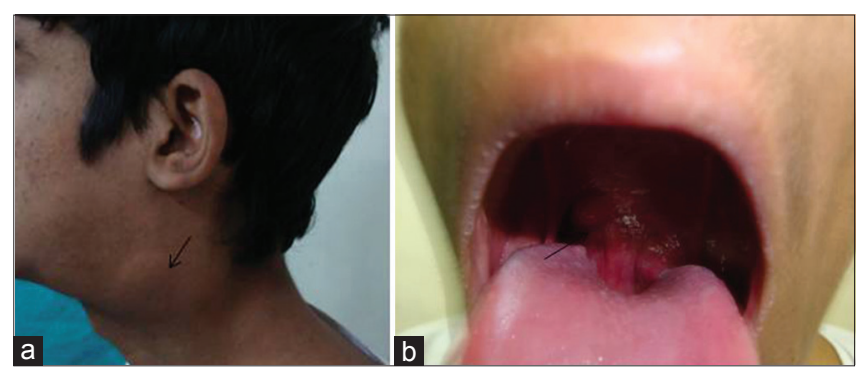

Figure 1: (a) Mass lesion in the left-side of neck near the angle of jaw (b) and intra-oral examination showing large pharyngeal mass displacing the uvula to right side

The neuroradiological intervention was uneventful, at the end of which the patient was reversed from residual neuromuscular blockade with neostigmine and gycopyrrolate. Oropharyngeal suction was done under direct laryngoscopy ensuring proper care of the pharyngeal mass. Trachea was extubated uneventfully after the patient became fully conscious.

The carotid body is located at the carotid artery bifurcation. It is a chemoreceptor cell, which stimulates with decrease oxygen tension, increase $\mathrm{CO}_{2}$ tension and increase in hydrogen ion concentration, leading to an increase in respiratory rate, tidal volume, blood pressure and heart rate. ${ }^{[1]}$ The carotid bifurcation lies close to many important structures, hence, expansion of a carotid tumour leads to cranial nerve palsies. The usual presentation of the tumour is that of slow growing painless lump in the neck. Presence of a bruit suggests significant compression of the artery. Surgical excision of such tumour is not only frightful for the surgeon but also poses challenges for the anaesthesiologist in the forms of hypertensive crises during surgical manipulation, sudden severe haemorrhage, reflex bradycardia, sudden hypotension and risk of post-operative neurological deficit. ${ }^{[2]}$ Although the surgical removal remains the treatment of choice, it is carried out in tumours less than $5 \mathrm{~cm}$ diameter. Large tumours may require pre-operative embolisation to decrease vascularity and hence, reduce intra-operative blood loss and transfusion. ${ }^{[3,4]}$ Embolisations in interventional neuroradiology suite have special anaesthetic concerns because of limited access to the patient and airway. The anaesthetic goals during INR are to keep the patient immobile, ensure rapid recovery for neurological examination, anticoagulation and maintenance of haemodynamic stability. ${ }^{[5]}$ Large carotid tumour with intra-oral protrusion presents several potential difficulties for the attending anaesthesiologist. The primary concern is obstruction of airway owing to the large oropharyngeal mass. There is also a possibility of fatal bleeding from the vascular tumour if injured during the course of oropharyngeal manipulations such as suction, laryngoscopy and endotracheal intubation. Awake fibreoptic intubation in such a scenario is
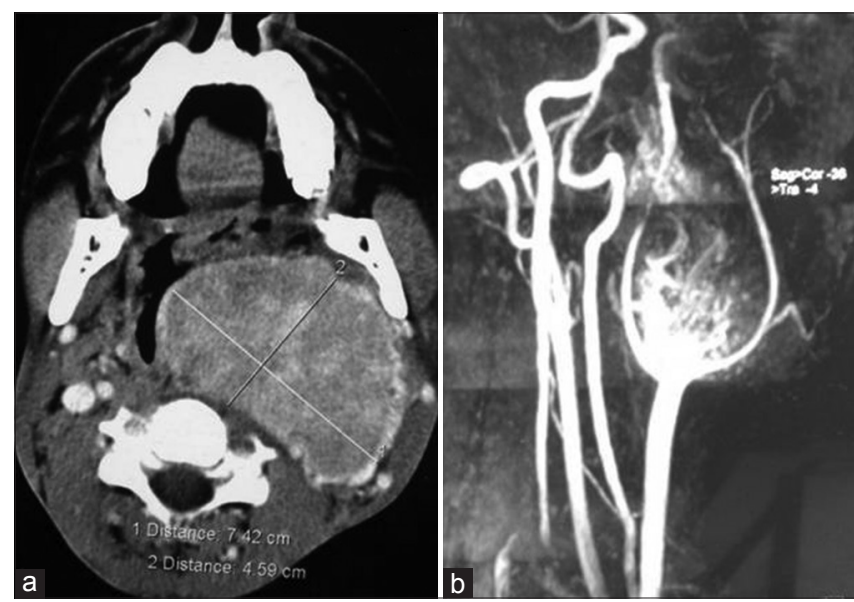

Figure 2: (a) Contrast enhanced computed tomographic scan showing heterogeneously enhancing mass lesion in left parapharyngeal space (b) and digital subtraction angiography shows hypervascular mass lesion in left side perfused by the facial branch of the external carotid artery

also not devoid of complications as rail-loading of tracheal tube may injure the vascular tumour. A careful preoperative evaluation to localise the site of obstruction and planning for airway management in advance may prevent complications of failed intubation.

To conclude, large intra-orally protruded carotid body tumour may cause difficulty in intubation and may bleed profusely in case of any injury, with fatal consequences. In this context, the role of utmost care during perioperative oropharyngeal manipulations may not be overemphasised.

\section{REFERENCES}

1. McLafferty RB. Preoperative embolization in managing carotid body tumors. Endovasc Today 2005:49-53.

2. Van WK. Anaesthetic management for the excision of carotid body tumours-- A report of two cases. Singapore Med J 1985;26:139-41.

3. Puggioni A, Delis KT, Fields CE, Viozzi CF, Kallmes DF, Gloviczki P. Large symptomatic carotid body tumor resection aided by preoperative embolization and mandibular subluxation. Perspect Vasc Surg Endovasc Ther 2005;17:21-8.

4. Li J, Wang S, Zee C, Yang J, Chen W, Zhuang W, et al. Preoperative angiography and transarterial embolization in the management of carotid body tumor: A single-center, 10-year experience. Neurosurgery 2010;67:941-8.

5. Young WL, Pile-Spellman J. Anesthetic considerations for interventional neuroradiology, Anesthesiology 1994;80:427-56.

\begin{tabular}{|l|l|}
\hline \multicolumn{2}{|c|}{ Access this article online } \\
\hline Quick Response Code: & Website: \\
\hline & www.jnaccjournal.org \\
\cline { 2 - 2 } & \\
\hline
\end{tabular}

